\title{
Evidence Based Beta-Blocker Therapy of Pediatric Heart Failure
}

\author{
Buchhorn R \\ Department of Pediatric, Caritas Krankenhaus Bad Mergentheim, Germany \\ "Corresponding Author: Buchhorn R, Department of Pediatric, Caritas Krankenhaus Bad Mergentheim, \\ Germany,E-mail: Reiner.Buchhorn@ckbm.de
}

\section{THE BURDEN OF PEDIATRIC HEART FAILURE}

A simplified picture from different sources 1 about the global burden of pediatric heart failure will help us to identify the specific problems in childhood heart failure:

$>$ Two thirds of children who die from heart failure are infants

$>$ The main cause of childhood heart failure in Europe and the US are congenital heart defects $(80 \%$ overall, $40 \%$ left-to-right shunts and 20\% complex heart defects)

$>$ The main causes of childhood heart failure in the developing world are acquired heart disease such as anemia and infections

$>$ Heart failure is one of the main causes of infant mortality worldwide

In 2006 we published data from 345 grownups with congenital heart defects that showed a growing incidence of heart failure during follow up 2. Recently long term (60 years!) data for more than 10000 Scandinavian children with operated congenital heart defects 3 showed that $43 \%$ of these patients died from heart failure and $20 \%$ from sudden cardiac death. Added to this there were $21 \%$ fatal perioperative complications. Other problems, such as endocarditis, stroke, aortic dissection, bleeding and embolism playing a subordinate role. The mean age at death of $14 \pm 16$ years indicates that many patients whose cause of death was heart failure are children. Heart failure indicated by elevated brain natriuretic peptide levels is a marker of prognosis in children 4 and adults with congenital heart disease 5. Cardiovascular mortality is also increased in patients with simple congenital heart defects like ventricular and atrial septal defects 6 .

\section{CliniCAL TRIALS IN PEDIATRIC HEART FAILURE}

Unfortunately, despite the fact that most of the children who died from heart failure in Europe and the US are infants with congenital heart defects, the main focus of heart failure research in pediatric cardiology has been in older children with ventricular dysfunction23. It is Robert Shaddy who published the first cases of metoprolol treatment for children with cardiomyopathies 7. He initiated the US carvedilol trial 8, a multicenter prospective randomized trial with carvedilol in children older than 1 year and suffering from heart failure from multiple etiologies. Unfortunately he made the same mistake like as I did in the so called BB-GUCH trial 9: Since the partners did not seem to trust beta blocker treatment in childhood heart failure and because they were concerned about the possibility of severe complications both trials recruited children with mild heart failure and low neurohormonal activities indicated by low BNP values. We decide for a cut off value of $100 \mathrm{pg} / \mathrm{ml}$ while the mean BNP value of $110 \mathrm{pg} / \mathrm{ml}$ in the US carvedilol trial was even lower. As we know today, we need thousands of such NYHA 2 patients and very long-term observation times to find a significant survival benefit in such trials and this will probably never be possible in pediatric cardiology. Nobody can explain why such an underpowered trial with very low dose carvedilol in 106 children with ventricular dysfunction with low BNP values should prove the results from more than 20000 adults with left ventricular dysfunction in well conducted prospective randomized trials 10 . However, if we summarize all these underpowered trials with carvedilol in 228 children with left ventricular dysfunctions in a meta-analysis we find the expected survival benefit (OR 0.57; 0.33-0.97) 11. Indeed children are not miniature 
adults, but they are humans: Perhaps for the first time in medical history pediatricians are calling for a life-saving therapy for children to be used only before appropriate child studies are carried out. It shows a degree of cynicism if such studies have not been carried out for more than 20 years.

I could only find 4 prospective randomized trials in infants with heart failure due to congenital heart defects 12-15 (table 1), three of these studies are investigator initiated trials from Germany, Turkey and India. In contrast to enalapril and digoxin, beta blockers improve clinical signs of heart failure and neurohormonal activation. The effect on mortality remains unclear in these small trials, but is similar to the $13 \%$ in the enalapril and placebo group of the US trial. For this trial 230 from the 533 infants of the Single Ventricle Reconstruction Trial who were eligible were recruited, and 31 died. The overall one year mortality of 555 infants with a single right ventricle was higher $(30 \%)$ 16.

Table1. Prospective randomized trials in infants with heart failure due to congenital heart defects.

\begin{tabular}{|l|l|l|l|l|}
\hline & $\begin{array}{l}\text { CHF- } \\
\text { Pro- } \\
\text { Infant }^{\text {14 }}\end{array}$ & $\begin{array}{l}\text { US- } \\
\text { Enala } \\
\text { pril }^{\mathbf{1 2}}\end{array}$ & $\begin{array}{l}\text { VSD- } \\
\text { PHF }\end{array}$ & $\begin{array}{l}\text { Elkir } \\
\text { an et } \\
\text { al }^{\mathbf{1 3}}\end{array}$ \\
\hline N & 20 & 185 & 80 & 37 \\
\hline $\begin{array}{l}\text { Drug } \\
\text { lol/ } \\
\text { Dig+Diur } \\
\text { etics }\end{array}$ & $\begin{array}{l}\text { Enalap } \\
\text { ril/ } \\
\text { Placeb } \\
\text { o }\end{array}$ & $\begin{array}{l}\text { Proprano } \\
\text { lol/ } \\
\text { Dig+Diur } \\
\text { etics }\end{array}$ & $\begin{array}{l}\text { Digo } \\
\text { xin/ } \\
\text { Place } \\
\text { bo }\end{array}$ \\
\hline $\begin{array}{l}\text { Age } \\
\text { [Year } \\
\text { s] }\end{array}$ & 0.2 & 0.1 & 0.5 & 0.3 \\
\hline $\begin{array}{l}\text { CHD } \\
\text { [\%] }\end{array}$ & 100 & 100 & 100 & 100 \\
\hline $\begin{array}{l}\text { Diagn } \\
\text { osis }\end{array}$ & LRS/SV & SV & VSD & $\begin{array}{l}\text { LRS/ } \\
\text { SV }\end{array}$ \\
\hline $\begin{array}{l}\text { BNP } \\
\text { [pg/ml } \\
\text { ] }\end{array}$ & $\begin{array}{l}\text { NT-BNP } \\
17000\end{array}$ & $\begin{array}{l}\text { BNP } \\
82\end{array}$ & $?$ & $\begin{array}{l}\text { NT- } \\
\text { BNP } \\
1396 \\
2\end{array}$ \\
\hline $\begin{array}{l}\text { Morta } \\
\text { lity } \\
\text { [\%] }\end{array}$ & 20 & 13 & 3.7 & $?$ \\
\hline
\end{tabular}

\section{THE CURRENT TREATMENT OF PEDIATRIC} HEART FAILURE

It is unclear what the current practice in childhood heart failure is. I introduced beta blockers in the German guidelines in 2006 and probably Robert Ross introduced them in the Canadian guidelines in 2013. It is certain that preoperative beta blocker treatment remains highly controversial but I am surprised to see that more and more pediatric cardiologists routinely use beta blockers despite criticism from opinion leaders. However, published data from the US show that infants with a single ventricle are treated with diuretics (90\%), ACE inhibitors (38\%) and Digoxin (28\%). Only 4.2\% of these infants received propranolol17. For left ventricular dysfunction "National Prescribing Trends for Heart Failure Medications in Children" 18 showed an increase in the use of beta blockers from $10 \%$ in 2001 to $40 \%$ in 2005 , but no further increase up to 2010 after publication of the US carvedilol trial. From 13892 pediatric heart failure hospitalisations in the US 1014 children died (7,3\%) 19. Pediatric mortality is nearly twice as high as mortality in adults with heart failure 20 due to a $40 \%$ mortality reduction by beta blocker treatment measured in high volume clinical trials. The potential of saving 400 children's lives saved in the US alone should be an order to the opinion leaders in pediatric cardiology rethink their "nihilism" against beta blockers in pediatric heart failure, as recently published 21 .

\section{EVIDENCE BASED THERAPY OF INFANTS HEART FAILURE BASED UPON HRV ONLINE MONITORING}

We use heart rate variability (HRV) onlinemonitoring on our pediatric intensive care unit (PICU) to predict the impact of beta blockers on heart failure in each individual patient. We recently published our first results and could show that those patients with increasing total power and high frequency power have favorable long-term courses. Such an infant with Down's syndrome and VSD with a very high NT-Pro BNP value of $101000 \mathrm{pg} / \mathrm{ml}$ who was treated with dobutamine due to left ventricular dysfunction is shown in figure 1 . We start low dose carvedilol and could stop dobutamine after 24 hours while heart rate variability increase to normal values within one week and NT-Pro BNP decrease rapidly. The baby could be quickly weaned from ventilator and complete breastfeeding was established at the time of admission after 2 weeks. Up to the successful operation, treated with $0.7 \mathrm{mg} / \mathrm{kg}$ carvedilol, he was free of clinical heart failure with normal weight gain. The baby was successfully operated at the age of six month. 


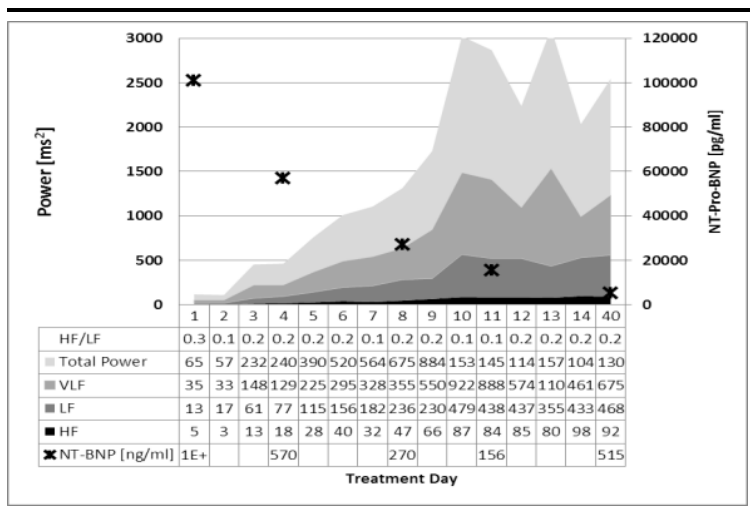

Figure1. HRV online Monitoring on the PICU while changing Dobutamine to Carvedilol
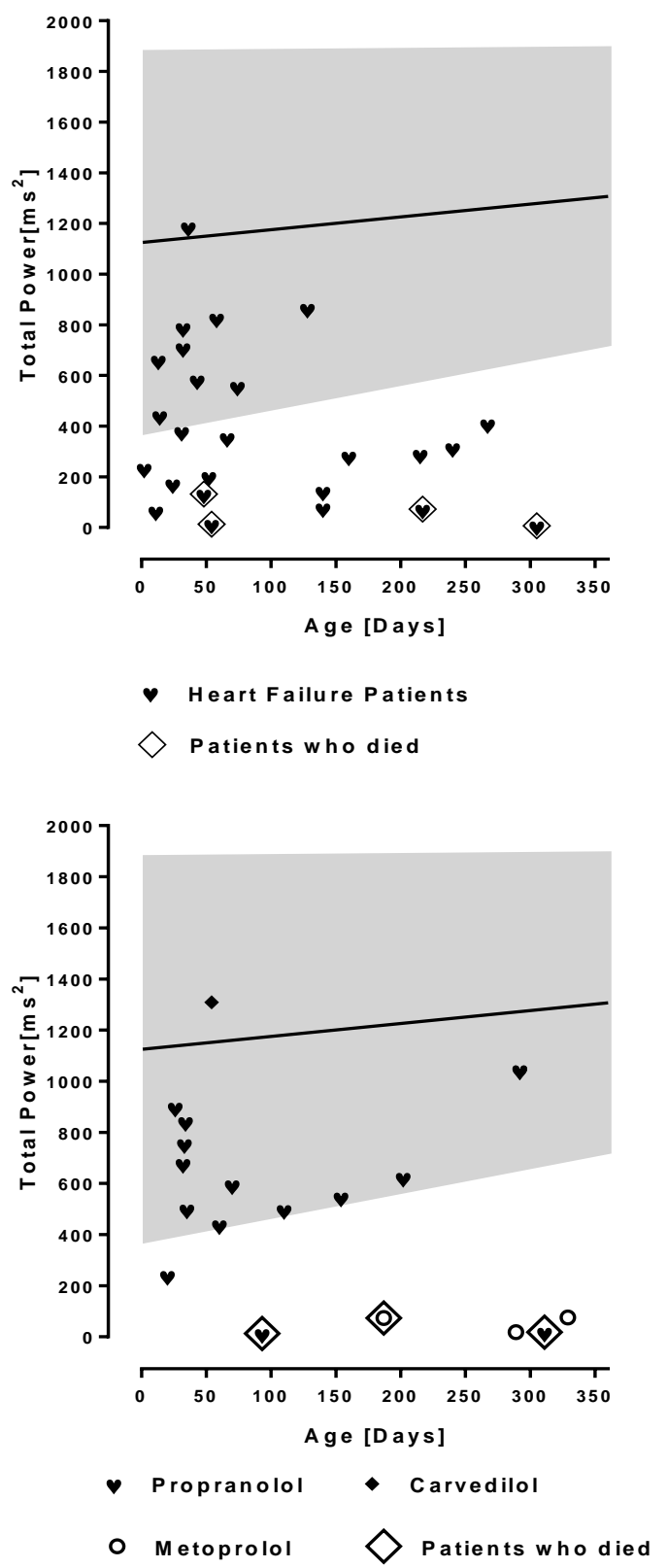

Figure2. 24 hours HRV online Monitoring in infants with heart failure on our PICU.

Today we have such HRV data from 28 infants with severe heart failure who were treated in our PICU (Figure 2a). Four of them died, three had a singular ventricle and one a hypertrohic cardiomyopathy due to a mitochondriopathy. Two had palliative care of cause infaust prognosis due to trisomy 18 and the mitochondriopathy, three of these infants are on beta blockers. Figure 2b shows 19 infants with severe heart failure who were treated in our PICU after initiation of a beta blocker (15 Propranolol, 3 Metoprolol and 1 Carvedilol). Propranolol and Carvedilol were successful in all preoperative infants and HRV increase to normal values as published in 200222. All these infants survive. However HRV remained very low in older infants with a complicated course after heart surgery most of all after palliation of a single ventricle, two of them and the baby with the mitochondriopathy died. Three infants are on metoprolol treated from the university hospitals that performed heart surgery. One infant after biventricular repair of pulmonary atresia had ongoing heart failure despite metoprolol, sildenafil, frusemide, hydro chlorothiazide and oxygen therapy. After 4 month of this unsatisfactory therapy we decide to change the cardio selective beta blocker metoprolol (24mg) to $15 \mathrm{mg}$ propranolol. HRV online monitoring on our PICU showed an impressive decrease of heart rate and increase of HRV (figure 3). The clinical improvement gives us the opportunity to stop therapy with sildenafil, frusemide and oxygen. NT-Pro-BNP drop down from 2413 to $837 \mathrm{pg} / \mathrm{ml}$. This case demonstrate that propranolol has extraordinary effects on heart rate and HRV in infants with heart failure compared to cardio selective beta blockers probably of cause its additional effects on $\beta 2$ - and central $\beta$ - receptors. Unfortunately other groups didn't proof our extraordinary good results with propranolol in infants with heart failure due congenital heart disease published in a prospective study in 200123 .

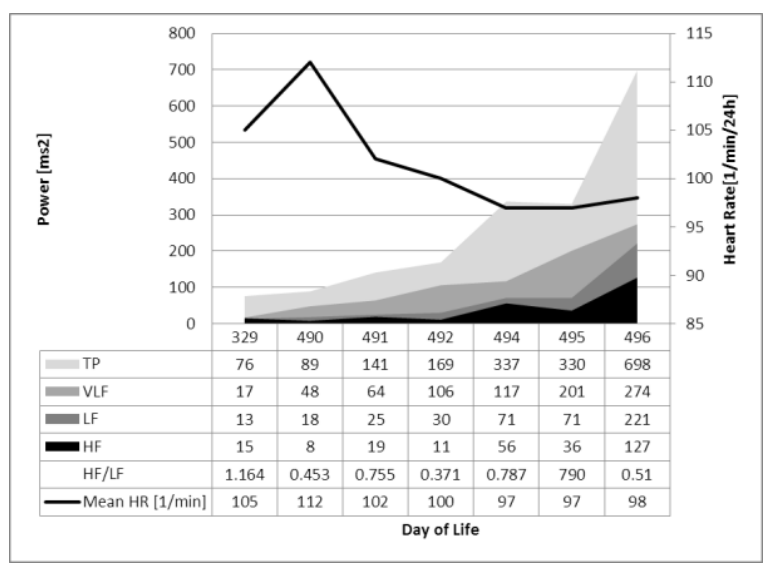

Figure3. HRV online Monitoring on the PICU while changing Metoprolol to Propranolol. 


\section{AUTONOMIC IMPRINTING-UNTREATED EARLY STRESS HAS LIFELONG CONSEQUENCES}

We developed a model called "autonomic imprinting", recently published in PLOS one 24 that should explain how early life stress impair growth and cognition and enhance the cardiovascular risk in later life25. Heart failure was only one of different causes of early life stress like intrauterine growth retardation and prematurity. We began to understand the impact of nutrition on the autonomic nervous system 26. Today we are able to show that our concept to prevent and to treat early life stress in children with congenital heart defects has longtime beneficial effects on the autonomic nervous system measured by 24 hour heart rate variability 27;28. We published our complete group (from a little Pediatric Department in Bad Mergentheim) of patients with operated congenital heart disease and cardiomyopathies as shown in figure 4: We changed our concept to treat heart failure in 2004. We intend to improve autonomic imprinting by heart failure with the use of propranolol without any use of diuretics in infants with heart failure. This current concept group with an age up to 12 years is the first complete published group with operated congenital heart disease who had supernormal HRV and obviously no autonomic dysfunction. Nearly $50 \%$ of our conventional treated patients with an age between 13 and 40 years have low HRV and in part severe autonomic dysfunction as published by other groups. Children with ventricular dysfunction had the lowest HRV despite beta blocker treatment and died during follow up or need heart transplantation $(\mathrm{N}=2)$.

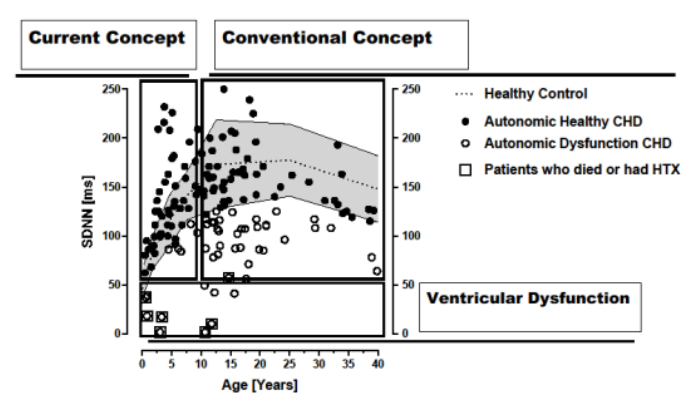

Figure4. 24-hour heart rate variability indicated by the parameter SDNN from our complete group of patients with operated congenital heart defects and/or cardiomyopathies. We changes preoperative therapy of heart failure in 2004 and observe nearly no patients with postoperative autonomic dysfunction during longtime follow up. As published by others groups, many patients with a conventional heart failure treatment in infancy developed autonomic dysfunction during follow up.

\section{REFERENCES}

[1] Schmaltz AA. Chronic congestive heart failure in infancy and childhood: new aspects of diagnosis and treatment. Klin Padiatr 2015; 227(1):3-9.

[2] Norozi K, Wessel A, Alpers V et al. Incidence and risk distribution of heart failure in adolescents and adults with congenital heart disease after cardiac surgery. Am J Cardiol 2006; 97(8):1238-1243.

[3] Raissadati A, Nieminen H, Haukka J et al. Late Causes of Death After Pediatric Cardiac Surgery: A 60-Year Population-Based Study. J Am Coll Cardiol 2016; 68(5):487-498.

[4] Inuzuka R, Tatebe S, Wakiguchi S et al. B-type natriuretic peptide at the early stage of univentricular circulation reflects inadequate adaptation to volume overload. Int $\mathbf{J}$ Cardiol 2012; 159(2):88-93.

[5] Miyamoto K, Takeuchi D, Inai $\mathrm{K}$ et al. Prognostic value of multiple biomarkers for cardiovascular mortality in adult congenital heart disease: comparisons of single-/twoventricle physiology, and systemic morphologically right/left ventricles. Heart Vessels 2016; 31(11):1834-1847.

[6] Videbaek J, Laursen HB, Olsen M et al. A Long-Term Nationwide Follow-Up Study of Simple Congenital Heart Disease Diagnosed in Otherwise Healthy Children. Circulation 2015.

[7] Shaddy RE, Olsen SL, Bristow MR et al. Efficacy and safety of metoprolol in the treatment of doxorubicin-induced cardiomyopathy in pediatric patients. Am Heart J 1995; 129(1):197-199.

[8] Shaddy RE, Boucek MM, Hsu DT et al. Carvedilol for children and adolescents with heart failure: a randomized controlled trial. JAMA 2007; 298(10):1171-1179.

[9] Norozi K, Bahlmann J, Raab B et al. A prospective, randomized, double-blind, placebo controlled trial of beta-blockade in patients who have undergone surgical correction of tetralogy of Fallot. Cardiol Young 2007; 17(4):372-379.

[10] Buchhorn R, McConnell ME. Beta blockers in childhood heart failure - why not? Int J Cardiol 2014; 175(1):211-212.

[11] Prijic S, Buchhorn R, Kosutic J et al. BetaBlockers (Carvedilol) in Children with Systemic Ventricle Systolic Dysfunction Systematic Review and Meta-Analysis. Rev Recent Clin Trials 2014; 9(2):68-75.

[12] Hsu DT, Zak V, Mahony L et al. Enalapril in infants with single ventricle: results of a 
multicenter randomized trial. Circulation 2010; 122(4):333-340.

[13] Elkiran O, Sandikkaya A, Kocak G et al. Evaluation by N-terminal prohormone of brain natriuretic peptide concentrations and ross scoring of the efficacy of digoxin in the treatment of heart failure secondary to congenital heart disease with left-to-right shunts. Pediatr Cardiol 2013; 34(7):1583-1589.

[14] Buchhorn R, Hulpke-Wette M, Hilgers R et al. Propranolol treatment of congestive heart failure in infants with congenital heart disease: The CHF-PRO-INFANT Trial. Congestive heart failure in infants treated with propanol. Int J Cardiol 2001; 79(2-3):167-173.

[15] Ramakrishnan S. Pediatric Heart Failure in the Developing World. Rev Recent Clin Trials 2014.

[16] Ohye RG, Schonbeck JV, Eghtesady P et al. Cause, timing, and location of death in the Single Ventricle Reconstruction trial. J Thorac Cardiovasc Surg 2012; 144(4):907-914.

[17] Ghelani SJ, Spurney CF, Martin GR et al. Impact of pharmacotherapy on interstage mortality and weight gain in children with single ventricle. Congenit Heart Dis 2013; 8(3):219-227.

[18] Moffett BS, Price JF. National prescribing trends for heart failure medications in children. Congenit Heart Dis 2015; 10(1):78-85.

[19] Rossano JW, Kim JJ, Decker JA et al. Prevalence, morbidity, and mortality of heart failure-related hospitalizations in children in the United States: a population-based study. J Card Fail 2012; 18(6):459-470.

[20] Wittlieb-Weber CA, Lin KY, Zaoutis TE et al. Pediatric versus adult cardiomyopathy and heart failure-related hospitalizations: a valuebased analysis. J Card Fail 2015; 21(1):76-82.
[21] Schranz D, Voelkel NF. "Nihilism" of chronic heart failure therapy in children and why effective therapy is withheld. Eur J Pediatr 2016; 175(4):445-455.

[22] Buchhorn R, Hulpke-Wette M, Nothroff J et al. Heart rate variability in infants with heart failure due to congenital heart disease: reversal of depressed heart rate variability by propranolol. Med Sci Monit 2002; 8(10):CR661-CR666.

[23] Alabed S, Sabouni A, Al Dakhoul S et al. Betablockers for congestive heart failure in children. Cochrane Database Syst Rev 2016;(1):CD007037.

[24] Willaschek C, Meint S, Rager K et al. Modified Clonidine Testing for Growth Hormone Stimulation Reveals alpha2-Adrenoreceptor Sub Sensitivity in Children with Idiopathic Growth Hormone Deficiency. PLoS ONE 2015; 10(9):e0137643.

[25] Buchhorn R, Meint S, Willaschek C. The Impact of Early Life Stress on Growth and Cardiovascular Risk: A Possible Example for Autonomic Imprinting? PLoS ONE 2016; 11(11):e0166447.

[26] Buchhorn R, Hauk F, Meint S, Willaschek C (2016). The impact of nutrition on the autonomic nervous system. Int J Food Nutr Sci 3 (3) :1-16

[27] Buchhorn R, Willaschek C, Norozi K (2016). Medical treatment of heart failure in infancy has long term effects on the autonomic nervous system - The concept of autonomic imprinting. Heart and Cardiol.

[28] Buchhorn R, Motz R, Norozi K (2016). Heart Failure in Infants with Congenital Heart Defects The Concept of Autonomic Imprinting. Heart and Cardiol.

Citation: Buchhorn R. Evidence Based Beta-Blocker Therapy of Pediatric Heart Failure. ARC Journal of Pediatrics. 2017; 3(1):4-8. doi:dx.doi.org/10.20431/2455-5711.0301002.

Copyright: () 2017 Authors. This is an open-access article distributed under the terms of the Creative Commons Attribution License, which permits unrestricted use, distribution, and reproduction in any medium, provided the original author and source are credited. 